- Regular Articles -

\title{
Possible Involvement of Insulin, Endogenous Opioids and Calcitonin Gene Related Peptide in Remote Ischaemic Preconditioning of Brain
}

\author{
Ashish K. Rehni, Nirmal Singh, ${ }^{*}$ and Amteshwar S. JAGGi \\ Department of Pharmaceutical Sciences and Drug Research, Punjabi University, Patiala-147002, India
}

(Received February 20, 2007; Accepted March 26, 2007)

\begin{abstract}
The present study has been designed to investigate the role of insulin, endogenous opioids and calcitonin gene related peptide (CGRP) on remote mesenteric ischaemic preconditioning induced reversal of global cerebral ischaemiareperfusion injury in mice. Bilateral carotid artery occlusion of $10 \mathrm{~min}$ followed by reperfusion for 24 hour was employed in present study to produce ischaemia and reperfusion induced cerebral injury in mice. Cerebral infarct size was measured using triphenyltetrazolium chloride staining. Short-term memory was evaluated using elevated plus maze. Inclined beam walking and resistance to lateral push response, tests were employed to assess motor incoordination. Bilateral carotid artery occlusion followed by reperfusion produced cerebral infarction and impaired short-term memory, motor co-ordination and lateral push response. A preceding episode of mesenteric artery occlusion for 15 min and reperfusion of $15 \mathrm{~min}$ (remote mesenteric ischaemic preconditioning) prevented markedly, ischaemia-reperfusion-induced cerebral injury measured in terms of infarct size, loss of short-term memory, motor coordination and lateral push response. Anti-insulin serum, naloxone (an opioid receptor antagonist) and $\alpha$-CGRP (8-37) (a selective CGRP receptor blocker) attenuated the neuroprotective effect of remote mesenteric ischaemic preconditioning. It may be concluded that neuroprotective effect of remote mesenteric ischaemic preconditioning probably is mediated through insulin, endogenous opioids and CGRP released as a consequence of mesenteric ischaemia and reperfusion in mice.
\end{abstract}

Key words — - remote preconditioning; ischaemic cerebral injury; insulin; opioids; calcitonin gene related peptide

\section{INTRODUCTION}

Ischaemic preconditioning has been reported to protect various organs including heart, ${ }^{1)}$ brain, ${ }^{2)}$ kidney, ${ }^{3)}$ small intestine, ${ }^{4)}$ skeletal muscle ${ }^{5)}$ and liver. ${ }^{6)}$ Remote ischaemic preconditioning refers to protective effect of brief episodes of ischaemia in one region, which provides protection to severe ischaemia in other distant organ. ${ }^{7)}$ Such a protective effect of remote ischaemic preconditioning has been produced in myocardium by prior occlusion and reperfusion of infrarenal aorta, ${ }^{8)}$ mesenteric, ${ }^{9)}$ renal ${ }^{10)}$ or femoral artery. ${ }^{11)}$ Recently we have observed that remote ischaemic preconditioning by mesenteric artery occlusion-reperfusion reverses the ischaemic injury in brain. ${ }^{12)}$

Mesenteric ischaemia has been observed to trigger an abrupt increase in the release of insulin from pancreas. ${ }^{13,14)}$ Insulin, per se, is documented to attenuate ischaemia-reperfusion injury in brain. ${ }^{15)} \mathrm{Be}$ sides, activation of opioid receptors has also been implicated in cardioprotective effect of remote ischaemic

\footnotetext{
*e-mail: nirmal puru@ rediffmail.com
}

preconditioning. ${ }^{8}$ 16) Calcitonin gene related peptide (CGRP) is one of the most potent dilator stimuli in the cerebral circulation. ${ }^{17)}$ Moreover, cardioprotective effect of remote preconditioning of heart has been ascribed to the increase in the concentration of plasma CGRP levels secondary to the remote ischaemia and the consequent CGRP receptor activation. ${ }^{18)} \mathrm{Ad}-$ ministration of CGRP in laboratory animals has been shown to reverse the ischaemic injury in brain. ${ }^{19)}$ Therefore, the present study has been designed to investigate the role of insulin, endogenous opioids and CGRP in the ameliorative effect of remote mesenteric ischaemic preconditioning on global ischaemia and reperfusion induced cerebral injury in mice.

\section{MATERIALS AND METHODS}

Male swiss albino mice weighing $25 \pm 2 \mathrm{~g}$, maintained on standard laboratory diet (Kisan Feeds Ltd., Mumbai, India) and having free access to tap water were employed in the present study. They were housed in the departmental animal house and were exposed to $12 \mathrm{hr}$ cycle of light and dark. All mice used in the study were naïve to elevated plus-maze test. The experiments were conducted in a semi-sound proof 
laboratory. The animal experiments were carried out as per the guidelines of Committee for the Purpose of Control and Supervision of Experiments on Animals (CPCSEA), Ministry of Environment and Forest, Government of India (Reg. No. -107/ 1999/ CPCSEA) .

\section{Raising of Anti-insulin Serum (AIS) in Guinea}

Pigs Anti-insulin serum was raised in Hartley guinea pigs (weighing $500 \pm 25 \mathrm{~g}$ ), using Arnim et al method with slight modifications. ${ }^{20)}$ Human insulin was incorporated in a water-oil emulsion based on a mixture of paraffin oil and lanolin (in a ratio of $1: 1$ : $3)$. A dose of $2 \mathrm{mg}$ insulin is injected in divided doses subcutaneously to guinea pigs on day 1 and day 21 and blood was withdrawn by cardiac puncture on day 28 and serum was isolated from the clotted blood by centrifugation.

Remote Mesenteric Ischaemic Preconditioning Mice were anaesthetized with chloral hydrate $(400 \mathrm{mg}$ $/ \mathrm{kg}, i . p$.). Body temperature of mice was maintained at $37^{\circ} \mathrm{C}$ using heated surgical platform. A median incision was made on the abdomen. Superior mesenteric artery was located, freed from surrounding tissue and a suture (numbered 5/0) was passed below it. ${ }^{12)}$ The mesenteric artery was occluded for $15 \mathrm{~min}$ by tying a shoelace knot and was untied for reperfusion of $15 \mathrm{~min}$. The abdomen was sutured in layers after the completion of one episode of remote mesenteric ischaemic preconditioning.

Ischaemia-reperfusion Induced Cerebral Injury Mice were anaesthetized using chloral hydrate $(400$ $\mathrm{mg} / \mathrm{kg}$, i.p.). A midline ventral incision was made in the neck to expose right and left common carotid arteries, which were isolated from surrounding tissue and vagus nerve. A cotton thread was passed below each of the carotid artery. Global cerebral ischaemia was induced by occluding the carotid arteries. After $10 \mathrm{~min}$ of global cerebral ischaemia, reperfusion was allowed for $24 \mathrm{hr}$. The incision was sutured back in layers. ${ }^{21)}$ The sutured area was cleaned with $70 \%$ ethanol and was sprayed with antiseptic dusting powder. The animals were shifted individually to their home cage and were allowed to recover.

Assessment of Cerebral Infarct Size At the end of $24 \mathrm{hr}$ of reperfusion after global cerebral ischaemia, animals were sacrificed by spinal dislocation and the brain was removed. The brain was kept overnight at $-4^{\circ} \mathrm{C}$. Frozen brain was sliced into uniform coronal sections of about $1 \mathrm{~mm}$ thickness. The slices were incubated in $1 \%$ triphenyltetrazolium chloride (TTC) at $37^{\circ} \mathrm{C}$ in $0.2 \mathrm{M}$ tris buffer ( $\mathrm{pH} \mathrm{7.4)} \mathrm{for} 20$ min. ${ }^{22)}$ TTC is converted to red formazone pigment by NAD and lactate dehydrogenase and thus stained the viable cells deep red. The infarcted cells have lost the enzyme and cofactor and thus remained unstained dull yellow. The brain slices were placed over glass plate. A transparent plastic grid with 100 squares in 1 $\mathrm{cm}^{2}$ was placed over it. Average area of each brain slice was calculated by counting the number of squares on either side. Similarly, number of squares falling over non-stained dull yellow area was also counted. Infarcted area was expressed as a percentage of total brain volume. Whole brain slices were weighed. Infarcted dull yellow part was dissected out and weighed. Infarct size was expressed as percentage of total wet weight of brain.

Evaluation of Short Term Memory Using Elevated Plus Maze Plus maze consisted of two open (16× $5 \mathrm{~cm})$ and two enclosed $(16 \times 5 \times 12 \mathrm{~cm})$ arms, connected by a central platform $(5 \times 5 \mathrm{~cm})$. The apparatus was elevated to a height of $25 \mathrm{~cm}$ above the floor. A fine line was drawn in the middle of the floor of each enclosed arm. All the animals were given a single trial/ day on plus maze. Each mouse was individually placed at the end of open arm facing away from central platform of the maze. The time taken by the mouse to enter from open arm with all the four legs into the enclosed arm was taken as transfer latency time (TLT). In case the animal did not enter the enclosed arm within $90 \mathrm{sec}$, it was gently pushed into the enclosed arm and TLT of $90 \mathrm{sec}$ was assigned to it. The animal was allowed to explore the maze for an additional $10 \mathrm{sec}$ after the measurement of TLT. ${ }^{23}$ ) The animal was exposed to elevated plus maze test for three consecutive days. ${ }^{24)}$ TLT recorded on the third day served as an index of acquisition whereas TLT measured on day four served as an index of memory. After recording day 3 TLT, the animal was subjected to global cerebral ischaemia for $10 \mathrm{~min}$ followed by reperfusion for $24 \mathrm{hr}$ and was again put to elevated plus maze test. Utmost care was taken not to change the relative location of plus maze with respect to any object serving as visual clue in laboratory.

Inclined Beam-walking Test Inclined beamwalking test was employed to evaluate fore and hind limb motor coordination. ${ }^{25)}$ Each animal was individually placed on a metallic bar $55 \mathrm{~cm}$ long and $1.5 \mathrm{~cm}$ wide, inclined at an angle of $60^{\circ}$ from ground. The 
motor performance of mouse was on a scale ranging from 0 to 4 . A grade of 0 was assigned to animal that could readily traverse the beam, grade 1 was given to animal demonstrating mild impairment, grade 2 was assigned to animal demonstrating moderate impairment, grade 3 was given to animal demonstrating severe impairment and grade 4 was assigned to animal completely unable to walk on the beam. Inclined beam-walking test was performed before global cerebral ischaemia and 12 and $24 \mathrm{hr}$ after global cerebral ischaemia and reperfusion.

Lateral Push Test Mouse was placed on a rough surface for firm grip and evaluated for resistance to lateral push from either side of shoulder. ${ }^{26)}$ The test was performed before global cerebral ischaemia and 12 and $24 \mathrm{hr}$ after global cerebral ischaemia and reperfusion. Mice with increased or decreased resistance to lateral push after global ischaemia were assigned + or - score respectively.

Experimental Protocol In total 9 groups were employed and each group comprised of 10 animals. Group I (Sham group) : Mouse was subjected to surgical procedure and suture was passed below the superior mesenteric artery but the artery was not occluded. After 30 min of surgery carotid arteries were isolated and thread was passed below it but the arteries were not occluded. After $10 \mathrm{~min}$, thread was removed and the animal was sutured back and allowed to recover for $24 \mathrm{hr}$.

Group II (Control group): Mouse was subjected to surgical procedure and suture was passed below the superior mesenteric artery but the artery was not occluded. After $30 \mathrm{~min}$ of surgery the mouse was subjected to $10 \mathrm{~min}$ global cerebral ischaemia followed by reperfusion for $24 \mathrm{hr}$.

Group III (Mesenteric preconditioning group): Mouse was subjected to $15 \mathrm{~min}$ of mesenteric artery occlusion followed by a reperfusion period of $15 \mathrm{~min}$. This was immediately followed by $10 \mathrm{~min}$ of global cerebral ischaemia and $24 \mathrm{hr}$ reperfusion.

Group IV (AIS control group): Mouse was administered AIS ( $0.1 \mathrm{ml}$, intravenous) 10 min prior to mesenteric artery isolation. Rest of procedure was same as described for group-II.

Group V (AIS treated preconditioning group): Mouse was administrated AIS ( $0.1 \mathrm{ml}$, intravenous) 10 min prior to mesenteric artery occlusion. Rest of procedure was same as described for group-III.
Group VI (Naloxone Control Group): Mouse was administrated naloxone (5 $\mathrm{mg} \mathrm{kg}^{-1}$, intravenous) 10 min prior to mesenteric artery isolation. Rest of procedure was same as described for group-II.

Group VII (Naloxone treated preconditioning group): Mouse was administrated naloxone $(5 \mathrm{mg}$ $\mathrm{kg}^{-1}$, intravenous) 10 min prior mesenteric artery occlusion. Rest of the procedure was same as described for group-III (Fig. 1).

Group VIII ( $\alpha$-CGRP (8-37) Control Group): Mouse was administrated $\alpha$-CGRP (8-37) $\quad(0.2 \mathrm{mg}$ $\mathrm{kg}^{-1}$, intravenous) $10 \mathrm{~min}$ prior to mesenteric artery isolation. Rest of procedure was same as described for group-II.

Group IX $(\alpha$-CGRP $(8-37)$ treated preconditioning group): Mouse was administrated $\alpha$-CGRP (8-37) $\left(0.2 \mathrm{mg} \mathrm{kg}^{-1}\right.$, intravenous) $10 \mathrm{~min}$ prior mesenteric artery occlusion. Rest of the procedure was same as described for group-III (Fig. 1).

Drugs and Chemicals Naloxone (Samarth

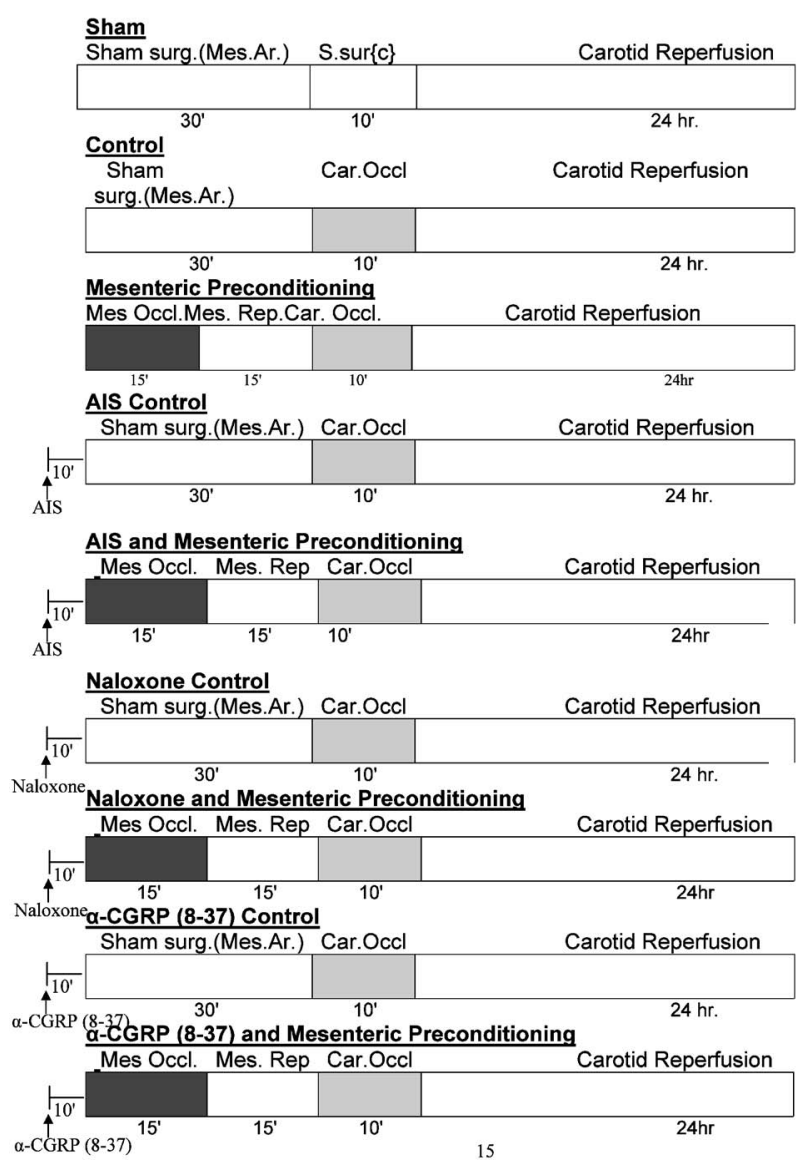

Fig. 1. Schematic Representation of Experimental Protocol Mes. $=$ Mesenteric, Ar. $=$ Artery, Occl. $=$ Occlusion, Rep. $=$ Reperfu sion, Car. $=$ Carotid Artery, S.sur $\{\mathrm{c}\}=$ Sham Surgery (Carotid Artery Isolation), surg. $=$ surgery. 
Pharma Pvt. Ltd., Mumbai, India), human $\alpha$-CGRP (8-37) (Calbiochem, San Diego, USA) and chloral hydrate (Riedel-deHaen, Germany) were dissolved in normal saline. All other chemicals used in the present study were of analar quality. All drug solutions were freshly prepared before use.

Statistical Analysis Statistical analysis for infarct size and TLT was done using one-way ANOVA followed by Tukey's multiple range test as post-hoc analysis. Statistical significance for lateral push and beam walking were calculated using Chi square and Wilcoxon Rank sum test respectively. A value of $p<$ 0.05 was considered to be statistically significant.

\section{RESULTS}

Effects of Mesenteric Preconditioning, AIS, Naloxone and $\alpha$-CGRP (8-37) on Ischaemia and Reperfusion Induced Cerebral Infarct Size In control group animals, global cerebral ischaemia followed by reperfusion produced significant cerebral infarction $(p<0.05)$ measured by volume and weight method, when compared to sham group animals. Remote mesenteric preconditioning markedly attenuated ischaemia and reperfusion induced increase in cerebral infarct size observed in control animals (Fig. 2 ). This observation indicates the neuroprotective effect of remote mesenteric preconditioning in cerebral ischaemia-reperfusion injury.

AIS (0.1 ml, intravenous) per se did not affect ischaemia-reperfusion induced cerebral infarction. However, AIS $(0.1 \mathrm{ml}$, intravenous) when injected prior to mesenteric preconditioning significantly $(p<$ 0.05 ) attenuated mesenteric preconditioning induced decrease in cerebral infarct size, occurred as a result of ischemia and reperfusion. Naloxone $\left(5 \mathrm{mg} \mathrm{kg}^{-1}\right.$, intravenous) per se did not show any marked effect on ischaemia and reperfusion induced increase in cerebral infarct size. However, naloxone $\left(5 \mathrm{mg} \mathrm{kg}^{-1}\right.$, intravenous), when injected prior to mesenteric preconditioning significantly $(p<0.05)$ prevented mesenteric preconditioning induced decrease in cerebral infarct size (Fig. 2). $\alpha$-CGRP (8-37) (0.2 $\mathrm{mg} \mathrm{kg}^{-1}$, intravenous) per se did not alter ischaemia and reperfusion induced increase in cerebral infarct size of control animals. Furthermore, $\alpha$-CGRP (837) (0.2 $\mathrm{mg} \mathrm{kg}^{-1}$, intravenous), when injected prior to mesenteric preconditioning significantly $(p<0.05)$ prevented mesenteric preconditioning induced decrease in cerebral infarct size (Fig. 2). The effects of AIS, naloxone and cGRP 8-37 were not statistically different on cerebral infarct size measured by volume and weight method.

Effects of Mesenteric Preconditioning, AIS, Naloxone and $\alpha$-CGRP (8-37) on Ischaemia and Reperfusion Induced Impairment of Short-term Memory and Motor Performance Sham group animals showed a significant decrease in day 4 TLT when compared to their day 3 TLT indicating normal

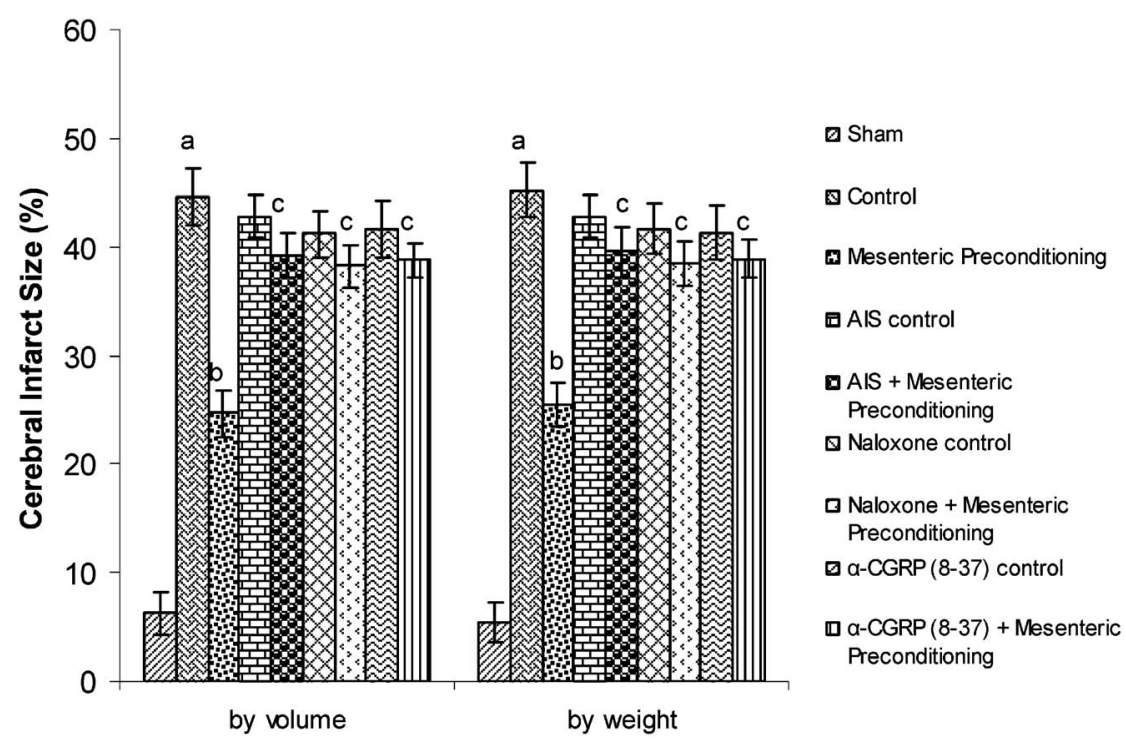

Fig. 2. Effect of Mesenteric Preconditioning, AIS, Naloxone and $\alpha$-CGRP (8-37) on Ischaemia and Reperfusion Induced Cerebral Infarct Size in Mice Measured by Volume and Weight Method

Values are mean \pm S.E. Statistical analysis for infarct size was done using one-way ANOVA followed by Tukey's multiple range test as post-hoc analysis. a $=p$ $<0.05$ vs. sham, $\mathrm{b}=p<0.05$ vs. control, $\mathrm{c}=p<0.05$ vs. mesenteric preconditioning. 
acquisition and retrieval of memory. In control group mice, global cerebral ischaemia followed by reperfusion significantly $(p<0.05)$ increased day 4 TLT when compared to day 4 TLT of sham reflecting impairment of memory. Mesenteric preconditioning significantly $(p<0.05)$ attenuated ischaemia-reperfusion induced increase in day 4 TLT of control, indicating reversal of ischaemia-reperfusion induced impairment of memory. AIS ( $0.1 \mathrm{ml}$, intravenous), naloxone (5 $\mathrm{mg} \mathrm{kg}^{-1}$, intravenous) and $\alpha$-CGRP (837) $\left(0.2 \mathrm{mg} \mathrm{kg}^{-1}\right.$, intravenous) per se did not modulate ischaemia-reperfusion induced increase in day 4 TLT of control. However, these treatments significantly $(p<0.05)$ attenuated mesenteric preconditioning induced decrease in day 4 TLT (Fig. 3).

In control group mice, global cerebral ischaemia followed by reperfusion produced significant $(p<$ $0.05)$ motor incoordination noted after 12 and $24 \mathrm{hr}$ of reperfusion when compared to sham group animals. Mesenteric preconditioning markedly prevented $(p<0.05)$ ischaemia-reperfusion induced motor incoordination. AIS (0.1 ml, intravenous), naloxone (5 mg kg${ }^{-1}$, intravenous) and $\alpha$-CGRP (837) $\left(0.2 \mathrm{mg} \mathrm{kg}^{-1}\right.$, intravenous) per se did not affect ischaemia-reperfusion induced motor incoordination. However, these treatments significantly $(p<0.05)$ attenuated mesenteric preconditioning induced decrease in motor incoordination (Fig. 4).
Global cerebral ischaemia followed by reperfusion produced a significant $(p<0.05)$ decrease in percentage of control mice demonstrating resistance to lateral push noted after 12 and $24 \mathrm{hr}$ of reperfusion when compared to sham group mice. Mesenteric preconditioning significantly $(p<0.05)$ prevented ischaemia-reperfusion induced decrease in percentage of mice demonstrating resistance to lateral push. AIS ( $0.1 \mathrm{ml}$, intravenous), naloxone $\left(5 \mathrm{mg} \mathrm{kg}^{-1}\right.$, intravenous) and $\alpha$-CGRP (8-37) $\left(0.2 \mathrm{mg} \mathrm{kg}^{-1}\right.$, intravenous) per se did not modify ischaemia-reperfusion induced decrease in percentage of mice demonstrating resistance to lateral push. However, these treatments significantly $(p<0.05)$ attenuated mesenteric preconditioning induced increase in percentage of mice demonstrating resistance to lateral push (Fig. 5).

\section{DISCUSSION}

Global cerebral ischaemia and reperfusion model employed in the present study is reported to simulate the clinical situation of cerebral ischaemia due to cardiac arrest or drowning. ${ }^{27,28)}$ Cerebral ischaemia has been reported to impair short-term memory because hippocampal neurons are susceptible to the deleterious effects of ischaemia and reperfusion ${ }^{29)}$ and hippocampus is involved in regulation of short term memory. Cerebral ischaemia is further documented

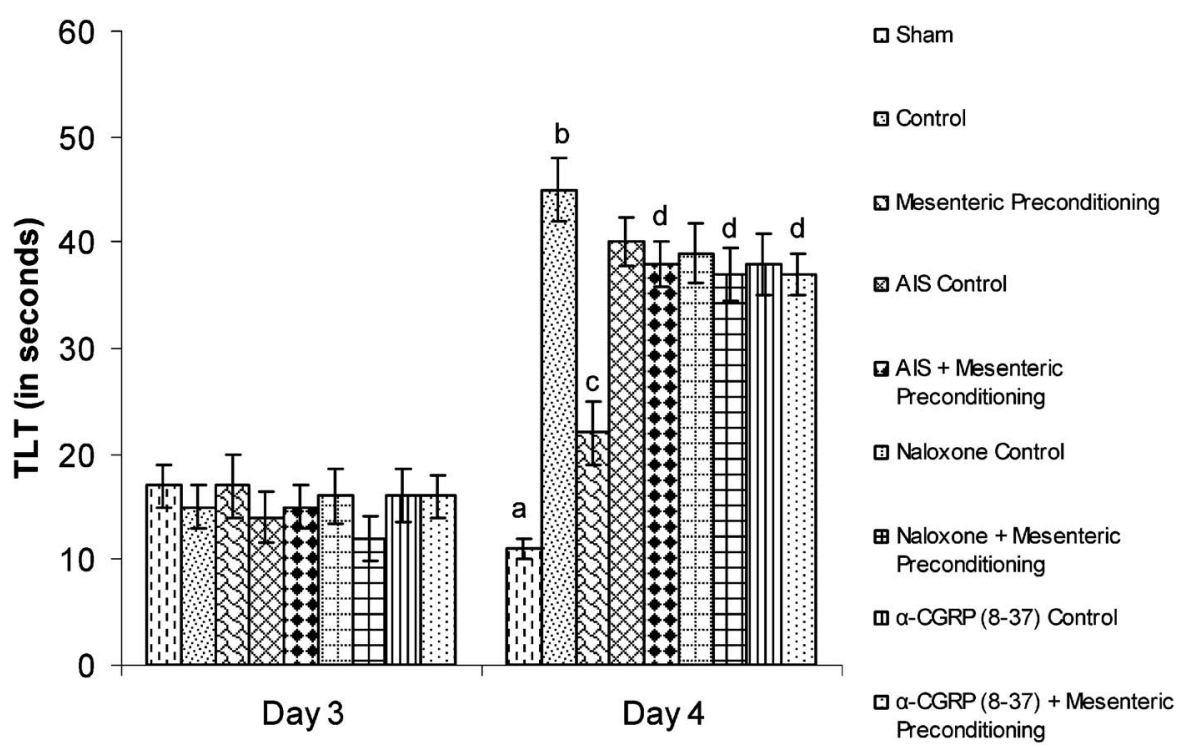

Fig. 3. Effect of Mesenteric Preconditioning, AIS, Naloxone and $\alpha$-CGRP (8-37) on Ischaemia and Reperfusion Induced Impairment of Short Term Memory in Mice

Values are mean \pm S.E. Statistical analysis for TLT was done using one-way ANOVA followed by Tukey's multiple range test as post-hoc analysis. a $=p<0.05$ day 4 TLT of sham vs. day 3 TLT of sham, $\mathrm{b}=p<0.05$ vs. day 4 TLT of sham, $\mathrm{c}=p<0.05$ vs. day 4 TLT of control, $\mathrm{d}=p<0.05$ vs. day 4 TLT of mesenteric preconditioning. 


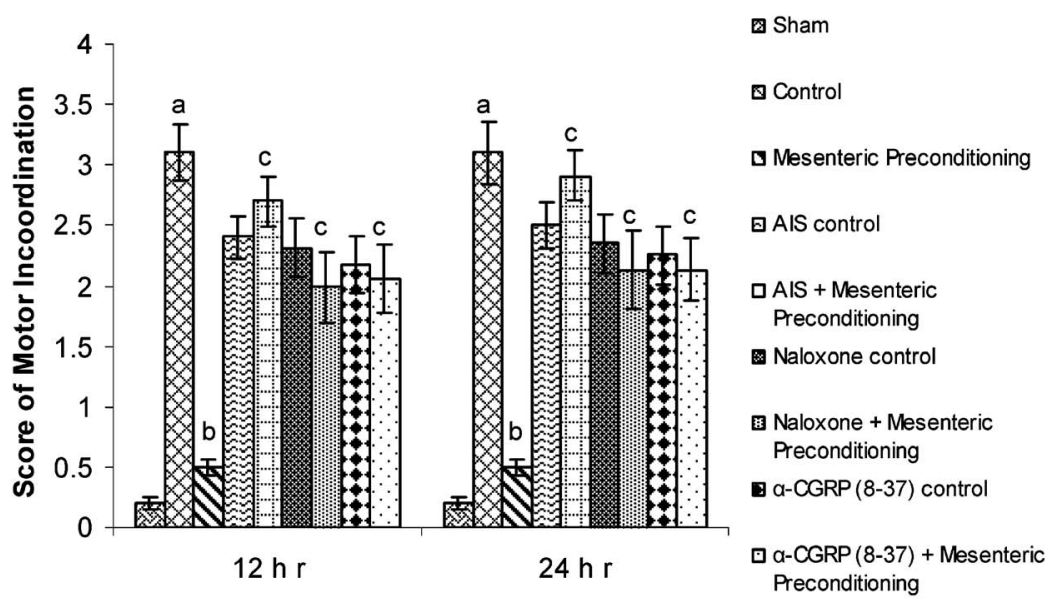

Fig. 4. Effect of Mesenteric Preconditioning, AIS, Naloxone and $\alpha$-CGRP (8-37) on Ischaemia and Reperfusion Induced Impairment of Motor Coordination Noted after 12 and $24 \mathrm{hr}$ of Reperfusion in Mice

Values are mean \pm S.E. Wilcoxon Rank sum test was used to test the statistical significance of difference between various groups. $\mathrm{a}=p<0.05$ vs. sham, $\mathrm{b}=p<$ 0.05 vs. control, $\mathrm{c}=p<0.05$ vs. mesenteric preconditioning.

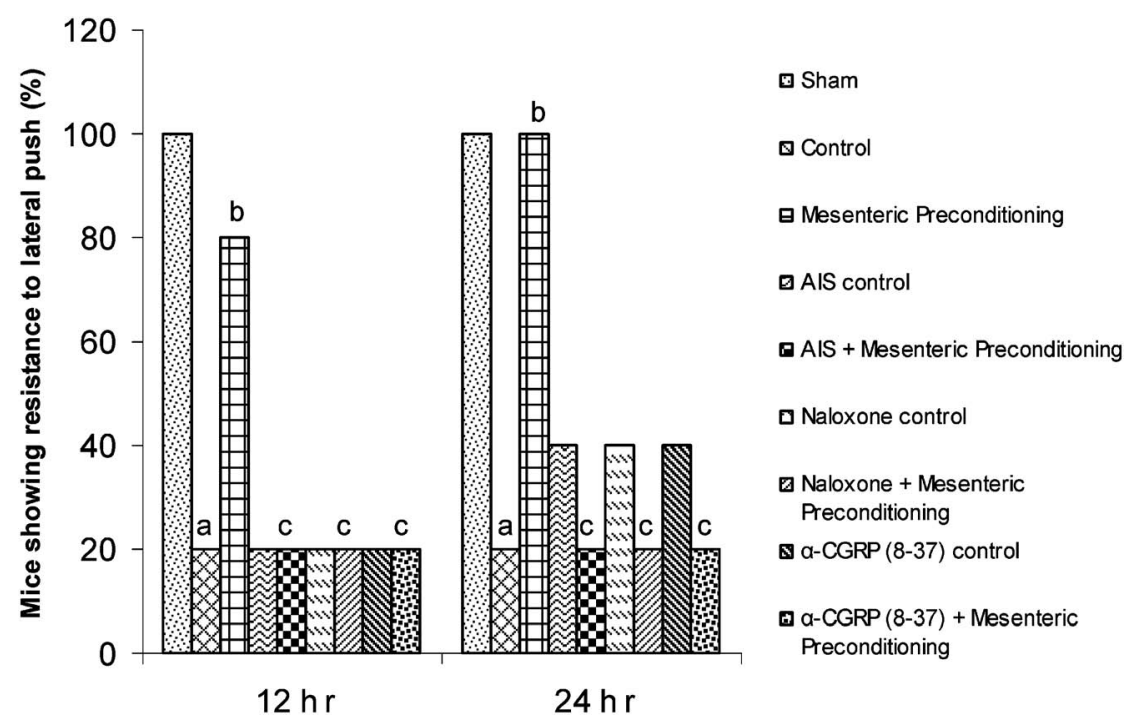

Fig. 5. Effect of Mesenteric Preconditioning, AIS, Naloxone and $\alpha$-CGRP (8-37) on Ischaemia and Reperfusion Induced Impairment of Resistance to Lateral Push Noted after 12 and $24 \mathrm{hr}$ of Reperfusion in Mice

Values are percentage of mice showing resistance to lateral push. Chi square test was used to test the statistical significance of difference between various groups. $\mathrm{a}=p<0.05$ vs. sham, $\mathrm{b}=p<0.05$ vs. control, $\mathrm{c}=p<0.05$ vs. mesenteric preconditioning.

to impair sensorimotor ability as well..$^{30)}$ Therefore, in the present investigation we employed elevated plus-maze test to assess short-term memory and inclined beam walking test and resistance to lateral push test for evaluation of sensorimotor ability. Global cerebral ischaemia reperfusion produced a significant rise in infarct size and induced impairment of short term memory as well as of motor coordination which are in line with earlier reports in our laboratory where. ${ }^{12,31)}$ In the present study remote mesenteric ischaemic preconditioning has been observed to prevent ischaemia and reperfusion induced increase in cerebral infarct size, impairment of short-term memory, motor incoordination and decrease in resistance to lateral push, which is in consonance with our earlier findings where remote mesenteric preconditioning has been shown to protect the ischaemic brain. ${ }^{12)}$ Besides, remote organ ischaemic preconditioning has been shown to protect brain from ischaemic damage following asphyxial cardiac arrest. ${ }^{32)}$ Further, in our study, the neuroprotective effect of remote mesenteric ischaemic preconditioning is attenuated by pretreatments with anti-insulin serum (AIS), naloxone and $\alpha$-CGRP (8-37). It has been 
reported long back that a single injection of AIS produces acute insulin deficiency in the blood.20) Insulin is noted to have neuroprotective effect and it has been shown to attenuate ischaemic brain damage independent of its hypoglycemic effect. ${ }^{15)}$ Recently, studies have reported that mesenteric ischaemia induces the release of insulin from pancreas into the blood circulation. ${ }^{13,14)}$ Therefore, the noted protective effect of remote mesenteric ischaemic preconditioning on cerebral injury may be mediated through the endogenous release of insulin, which is further supported by our study with AIS that attenuated the protective effect of mesenteric preconditioning on ischaemia-reperfusion induced cerebral injury. Thus, it may be deduced that insulin released as a result of an ischaemic insult to the mesentery may be mediating the resultant protection afforded by the remote preconditioning of brain. Naloxone has been documented to block opioid receptors, which are an integral part of the central nervous system. ${ }^{33)}$ Studies have revealed the implication of opioid receptor activation in the cardioprotective effect of remote preconditioning of heart. ${ }^{8}{ }^{16)}$ Hence, it may also be suggested that neuroprotective effect of remote mesenteric ischaemic preconditioning in the present study is due to the release of endogenous opioids and consequent activation of opioid receptors, which is further supported by our study with naloxone (a selective opioid receptor antagonist) that attenuated the protective effect of mesenteric preconditioning on ischaemiareperfusion induced cerebral injury. Calcitonin gene related peptide (CGRP) is a highly potent vasodilator in the vasculature of brain and is released in the nerve terminals present in the intestine. ${ }^{17)}$ Intravenous injection of CGRP in murine models has been shown to ameliorate the ischaemic injury in brain. ${ }^{19)}$ Moreover, cardioprotective effect of remote preconditioning of heart has been linked to CGRP receptor activation. ${ }^{18)}$ Therefore, it may be probable to speculate the release of calcitonin gene related peptide caused by remote mesenteric ischaemic preconditioning and resultant activation of the CGRP receptors to be responsible for the observed neuroprotection which is further supported by our study with $\alpha$-CGRP (8-37) [a selective CGRP receptor antagonist $\left.{ }^{34)}\right]$ that abolished the neuroprotection afforded by remote mesenteric ischaemic preconditioning. Besides, some of the pharmacological effects of endogenous opioids have been seen to be additive in nature with insulin as well as
CGRP suggesting their synergism to be playing a role in the protection afforded by the remote mesenteric ischaemic preconditioning. ${ }^{35,36)}$

On the basis of above discussion, it may be concluded that remote mesenteric ischaemic preconditioning exerts neuroprotective effect possibly, mediated through the release of insulin, endogenous opioids and calcitonin gene related peptide with consequent activation of their receptors. Nevertheless, further studies are required to elucidate the involvement of insulin, endogenous opioids and calcitonin gene related peptide in the neuroprotective manifestations of remote ischaemic preconditioning.

Acknowledgements The authors are grateful to Dr. A. K. Tiwary, Head, Department of Pharmaceutical Sciences and Drug Research, Punjabi University, Patiala, India for supporting this study and providing technical facilities for the work. The authors are also grateful to Dr. N. K. Talwar, Punjab Veterinary Vaccine Institute, Punjab Agriculture University, Ludhiana for providing technical help.

\section{REFERENCES}

1) Murray C.-E., Jennings R.-B., Reimer K.-A., Circulation, 74, 1124-1136 (1986).

2) Kitagawa K., Matsumoto M., Tagaya M., Hata R., Ueda H., Niinobe M., Handa N., Fukunaga R., Kimura K., Mikoshiba K., Brain Res., 528, 21-24 (1990).

3) Lee H.-T., Emala C.-W., Am. J. Physiol., 278, F380-F387 (2000).

4) Pajdo R., Brzozowski T., Konturek P.-C., Kwaiecien S., Konturek S.-J., Sliwowski Z., Pawlik M., Ptak A., Drazdowicz D., Hahn E.G., Eur. J. Pharm., 427, 263-276 (2001).

5) Mounsey R.-A., Pang C.-Y., Forrest C., Otolaryngol. Head Neck Surg., 107, 549-552 (1992).

6) Lloris-Carsi J.-M., Cejalvo D., ToledoPereyra L.-H., Calvo M.-A., Suzuki S., Transplant Proc., 25, 3303-3304 (1993) .

7) Przyklenk K., Bauer B., Ovize M., Kloner R.A., Whittaker P., Circulation, 87, 893-899 (1993)

8) Weinbrenner C., Schulze F., Sarvary L., Strasser R.-H., Cardiovas. Res., 61, 591-599 (2004)

9) Schoemaker R.-G., van Heigningen C.-L., 
Am. J. Physiol., 278, H1571-H1576 (2000) .

10) Gho B.-C.-G., Schoemaker R.-G., van Den Doel M.-A., Duncker D.-J., Verdouw P.-D., Circulation, 94, 2193-2200 (1996).

11) Birnbaum Y., Hale S.-L., Kloner R.-A., Circulation, 96, 1641-1646 (1997).

12) Rehni A.-K., Shri R., Singh M., Indian J. Exp. Biol., 45 (2007) (in press).

13) Phillips A.-R., Abu-Zidan F.-M., Farrant G.J., Zwi J.-L., Cooper G.-J., Windsor J.-A., Surgery, 129 (6), 730-735 (2001).

14) Phillips A.-R., Abu-Zidan F.-M., Bonham M.-J., Simovic M.-O., Cooper G.-J., Windsor J.-A., Eur. Surg. Res., 31 (6), 457-464 (1999).

15) Auer R.-N., J. Cereb. Blood Flow Metab., 11, 1006-1014 (1998).

16) Patel H.-H., Moore J., Hsu A.-K., Gross G.J., J. Mol. Cell Cardiol., 34, 1317-1323 (2002).

17) Edwards R.-M., Stack E.-J., Trizna W., J. Pharmacol. Exp. Ther., 257, 1020-1024 (1991).

18) Wolfrum S., Schneider K., Dominiak P., Dendorfer A., Regul. Pept., 127 (1-3), 217-224 (2005)

19) Holland J.-P., Sydserff S.-G.-C., Taylor W.A.-S., Bell B.-A., Stroke, 25, 2055-2059 (1994).

20) Arnim J., Grant R.-T., Wright P.-H., J. Physiol. (London) , 153, 131-145 (1960).

21) Himori N., Watanabe H., Akaike N., Kurasawa M., Itoh J., Tanaka Y., J. Pharmacol. Methods, 23, 311-327 (1990).

22) Bochelen D., Rudin M., Sauter A., J. Pharmacol. Exp. Ther., 288, 653-659 (1999).

23) Itoh J., Nabeshima T., Kameyama T., Psy- chopharmacology, 101, 27-32 (1990).

24) Zdenek H., Ivan K., Behav. Brain Res., 91, 83 -89 (1998).

25) Feeney D.-M., Boyeson M.-G., Linn R.-T., Murray H.-M., Dail W.-G., Brain Res., 211, 67-77 (1981).

26) Bederson J.-B., Pitts L.-H., Tsuji M., Nishimura M.-C., Davis R.-L., Bartowski H., Stroke, 17, 472-476 (1986).

27) Alonsode de Lecinana M., Diez-Tejedor E., Cearcellar F., Roda J.-M., Cerebrovasc. Dis., 11 (Suppl.I) , 20-30 (2001).

28) Neumar R.-W., Ann. Emerg. Med., 36, 483506 (2000)

29) Jenkins L.-W., Povlishock J.-T., Lewelt W., Miller J.-D., Becker D.-P., Acta Neuropathol., 5, 205-220 (1981).

30) Dobkin B.-H., Clin. Geriat. Med., 7, 507-523 (1991).

31) Gupta R., Singh M., Sharma A., Pharmacol. Res., 48 (2) , 209-215 (2003).

32) Dave K.-R., Saul I., Prado R., Busto R., Perez-Pinzon M.-A., Neurosci. Lett., 404 (12), 170-175 (2006).

33) Martin W.-R., Pharmacol. Rev., 35, 283-323 (1983).

34) Chiba T., Yamaguchi A., Yamatani T., Nakamura A., Morishita A., Inui T., Fukase M., Noda T., Fujita T., Am. J. Physiol., 256, E331-E335 (1989).

35) Bright G.-M., Kaiser D.-L., Rogol A.-D., Clarke W.-L., J. Clin. Endocrinol. Metab., 57, 213-216 (1983).

36) Smith F.-L., Welch S.-P., Dombrowski D.-S., Dewey W.-L., J. Pharmacol. Exp. Ther., 266 (3) , 1407-1415 (1993). 